\title{
A ALIMENTAÇÃO EM LISBOA NO DECURSO DA IDADE DO FERRO: RESULTADOS DAS ESCAVAÇÕES REALIZADAS NO NÚCLEO ARQUEOLÓGICO DA RUA DOS CORREEIROS (LISBOA, PORTUGAL)
}

\author{
THE DIET IN LISBON DURING THE IRON AGE: RESULTS OF THE EXCAVATIONS \\ UNDERTAKEN AT "RUA DOS CORREEIROS" (LISBON, PORTUGAL)
}

\author{
CLEIA DETRY* \\ JOÃO LUÍS CARDOSO*,** \\ JACINTA BUGALHÃO*,***
}

\begin{abstract}
Resumo: As escavações efectuadas no subsolo da baixa de Lisboa, no Núcleo Arqueológico da Rua dos Correeiros, permitiram a identificação de diversos contextos arqueológicos, de carácter habitacional e artesanal, dos séculos $\mathrm{V}$ a inícios do IV a.C. Esses contextos forneceram um assinalável conjunto de restos mamalógicos e malacológicos. No caso dos mamíferos, a maioria dos elementos são de animais domésticos (vaca, ovelha, cabra, porco, cavalo e cão), com uma reduzida representação de animais caçados (veado). Também a presença de moluscos demonstra a utilização de recursos aquáticos.

Estes resultados permitem sobretudo a reconstituição da dieta alimentar e, por via dela, das características económicas e até sociais do respectivo segmento da população que então ocupava a área ribeirinha da urbe.
\end{abstract}

Palavras-Chave: Zooarqueologia, Mamíferos, Moluscos, Idade do Ferro, Lisboa

\begin{abstract}
Excavations carried out in a basement of downtown Lisbon, in the Archaeological Centre of Rua dos Correeiros, allowed the identification of several archaeological contexts, namely of residential and industrial type, dated from the $5^{\text {th }}$ century to early $4^{\text {th }}$ century BC. These contexts provided a remarkable set of mammalogical and malacological remains. In the case of mammals most elements came from domestic animals (cattle, sheep, goat, pig, horse and $\operatorname{dog}$ ), with a reduced representation of hunted animals (red deer). The presence of shellfish demonstrates the use of water resources.

These results allow mainly the reconstitution of the diet and, through it, economic and even social characteristics of the respective segment of the population who then habited the riverside area of the city.

Key-words: Zooarchaeology, Mammals, Mollusks, Iron Age, Lisbon
\end{abstract}

* UNIARQ, Centro de Arqueologia da Universidade de Lisboa Faculdade de Letras da Universidade de Lisboa. Alameda da Universidade. 1600-214 Lisboa. Portugal. Correo-e: cdetry@gmail.com

** Universidade Aberta. Palácio Ceia. Rua da Escola Politécnica, 141. 1269-001 Lisboa. Portugal. Centro de Estudos Arqueológicos do Concelho de Oeiras/Câmara Municipal de Oeiras. Fábrica da
Pólvora. Estrada das Fontainhas. 2745-613 Barcarena. Portugal. Correo-e: cardoso18@netvisao.pt

*** Direcção-Geral do Património Cultural. Palácio Nacional da Ajuda, 1349-021 Lisboa. Portugal. Correo-e: jacintabugalhao@ gmail.com. 


\section{INTRODUÇÃO}

Apresenta-se o estudo da fauna recuperada nos níveis datados da Idade do Ferro, identificados nas escavações realizadas no subsolo dos edifícios da baixa de Lisboa (Fig. 1 e 2), onde actualmente está instalado o Núcleo Arqueológico da Rua dos Correeiros (NARC).

As escavações decorreram de 1991 a 1996 sob direcção de Jacinta Bugalhão, tendo sido identificadas sucessivas ocupações humanas, da Idade do Ferro e das épocas Romana, Medieval e Moderna. Os contextos sidéricos foram alvo de estudo monográfico de Elisa de Sousa (2014).

Os materiais faunísticos do Período Romano foram estudados por Silvia Valenzuela (Valenzuela 2014) e do Período Medieval por Marta Moreno-García e Sónia Gabriel (Moreno-García e Gabriel 2001).

Nos níveis da Idade do Ferro foram identificados um total de 115 ossos e dentes de mamíferos e 26 restos de conchas de moluscos. O conjunto, embora menor que os dos períodos posteriores, integra as mesmas espécies, sendo constituído por bovinos (Bos taurus), caprinos (Ovis aries e Capra hircus), veado (Cervus elaphus), suídeos (Sus sp.) e cão (Canis familiaris), a que se somam dois elementos pertencentes a equídeo (Equus sp.). Os moluscos são típicos de água salobra e salgada, encontrando-se a ostra ( $O S$ trea edulis) e amêijoa-boa (Ruditapes decussatus) entre os mais comuns.

Os restos analisados são sobretudo resultado da acumulação dos despojos alimentares das populações que utilizaram estes espaços durante a Idade do Ferro, sendo que no caso do gado bovino e equídeo estes foram ainda provavelmente utilizados, durante a sua vida, para transporte e tracção na agricultura.

\section{O SÍTIO: CARACTERÍSTICAS GERAIS DA INTERVENÇÃO ARQUEOLÓGICA, ESTRATIGRAFIA E CRONOLOGIA}

No âmbito das obras de ampliação das instalações do então Banco Comercial Português (BCP), num conjunto de edifícios implantados entre a Rua Augusta e a Rua dos Correeiros em Lisboa (fig. 3), realizaram-se, entre 1991 e 1995, escavações arqueológicas que revelaram um conjunto de estruturas representativas de vários períodos históricos. Todo o conjunto posto a descoberto foi alvo de um projeto de musealização, constituindo-se assim o NARC, aberto à visita pública desde Junho de 1995.
A intervenção arqueológica revelou um amplo e imbricado conjunto de contextos arqueológicos e urbanísticos, estando presentes as principais fases de ocupação urbana da zona ribeirinha de Lisboa, desde os contextos pós-pombalinos, aos elementos arquitectónicos e construtivos característicos da construção pombalina (2. ${ }^{a}$ metade do século XVIII); a cosmopolita cidade dos Descobrimentos e os arrabaldes ribeirinhos medievais; uma necrópole datada da transição da Era e a ocupação industrial e portuária de época imperial romana (Bugalhão 2001: 18-33).

A primeira ocupação humana identificada no espaço hoje ocupado pelo NARC, cuja cronologia se situa entre o século $\mathrm{V}$ e os inícios do século IV a.C. (Sousa 2014: 214), enquadra-se no contexto de uma acentuada expansão urbanística. A cidade cresce na direcção do rio e seu esteiro, surgindo um bairro portuário e comercial. Desconhece-se para já a extensão e densidade urbana deste bairro, uma vez que os contextos do NARC são os únicos com leitura arquitectónica conhecida e que, mesmo neste sítio, foram escavados apenas dois sectores, pois, na restante área de intervenção, a opção pela musealização das estruturas romanas impediu o acesso aos níveis de ocupação anteriores.

O sector $1 \mathrm{NE}$ foi escavado na fase final da intervenção e revelou apenas contextos estratigráficos, sem qualquer estrutura. Foram escavadas as camadas $64,65,120$ e 124, que poderão corresponder ao abandono da área e as camadas 67 e 76, que poderão corresponder a níveis de ocupação. Não foram identificadas diferenças ao nível do espólio cerâmico (Sousa 2014: 64-66).

O sector $3 \mathrm{SE} / 3$ Este foi escavado de forma descontínua ao longo de quatro anos, à medida que a área ia ficando disponível para intervenção. Foi identificado conjunto de sete compartimentos de carácter aparentemente habitacional (com embasamento em pedra, paredes com estrutura vegetal revestida a barro, cobertura vegetal também revestida a barro, pavimento de argila e lareira central) e um forno cerâmico (fig. 4). Neste conjunto distinguem-se duas fases construtivas (Sousa 2014: 69-71), embora, uma vez mais, não se observem distinções cronológicas, ao nível do espólio cerâmico, entre estas duas fases ou ainda para os momentos de construção, ocupação e abandono das estruturas (Sousa 2014: 81).

A estratigrafia encontrava-se razoavelmente preservada de perturbações pós-deposicionais antrópicas. Contudo, o seu registo é bastante complexo devido a múltiplos fatores, tais como: a intensa dinâmica 


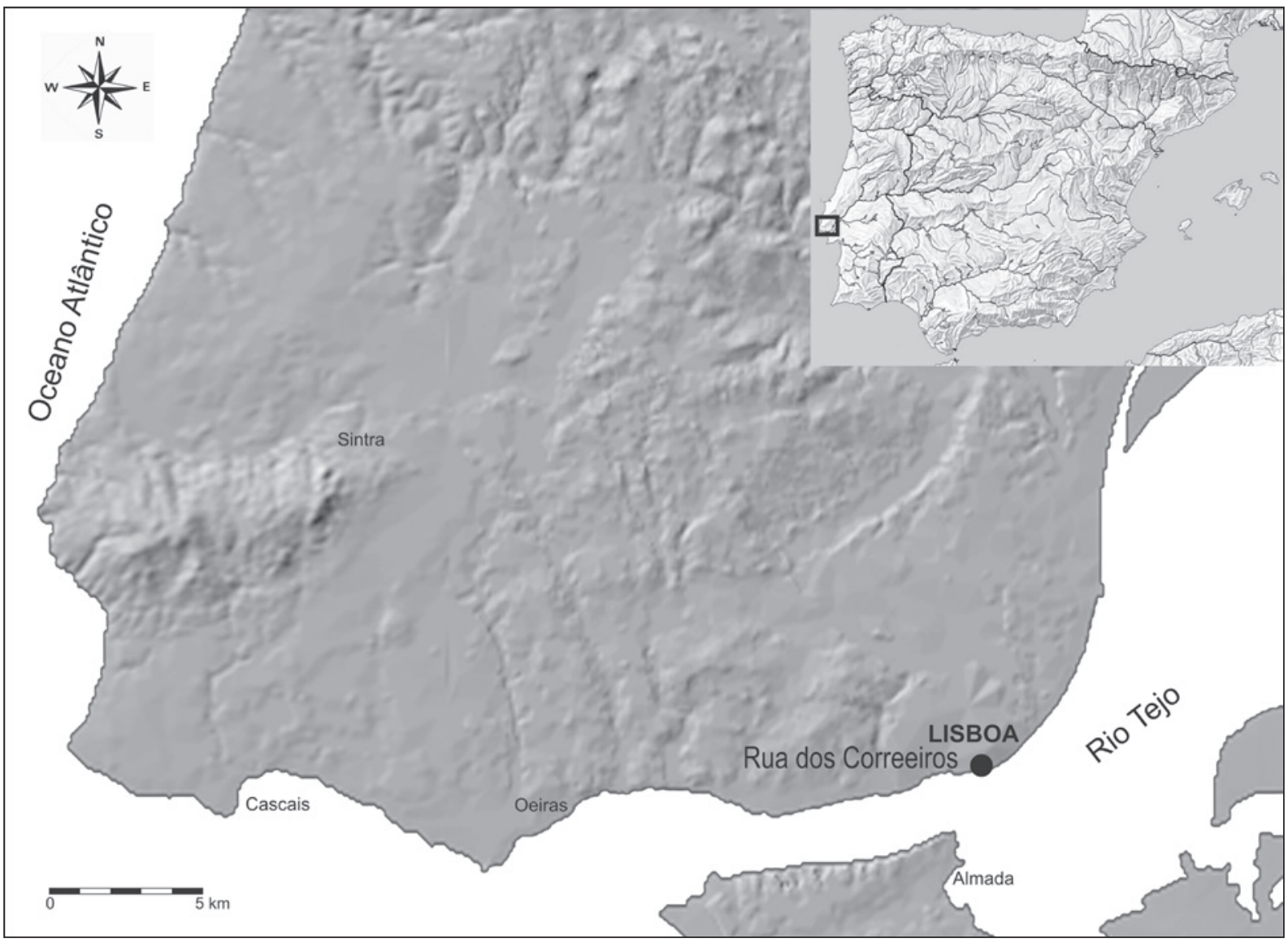

Figura 1. Localização do povoado sidérico de Olisipo (Lisboa)

Figura 2. Localização da zona do NARC na baixa lisboeta.

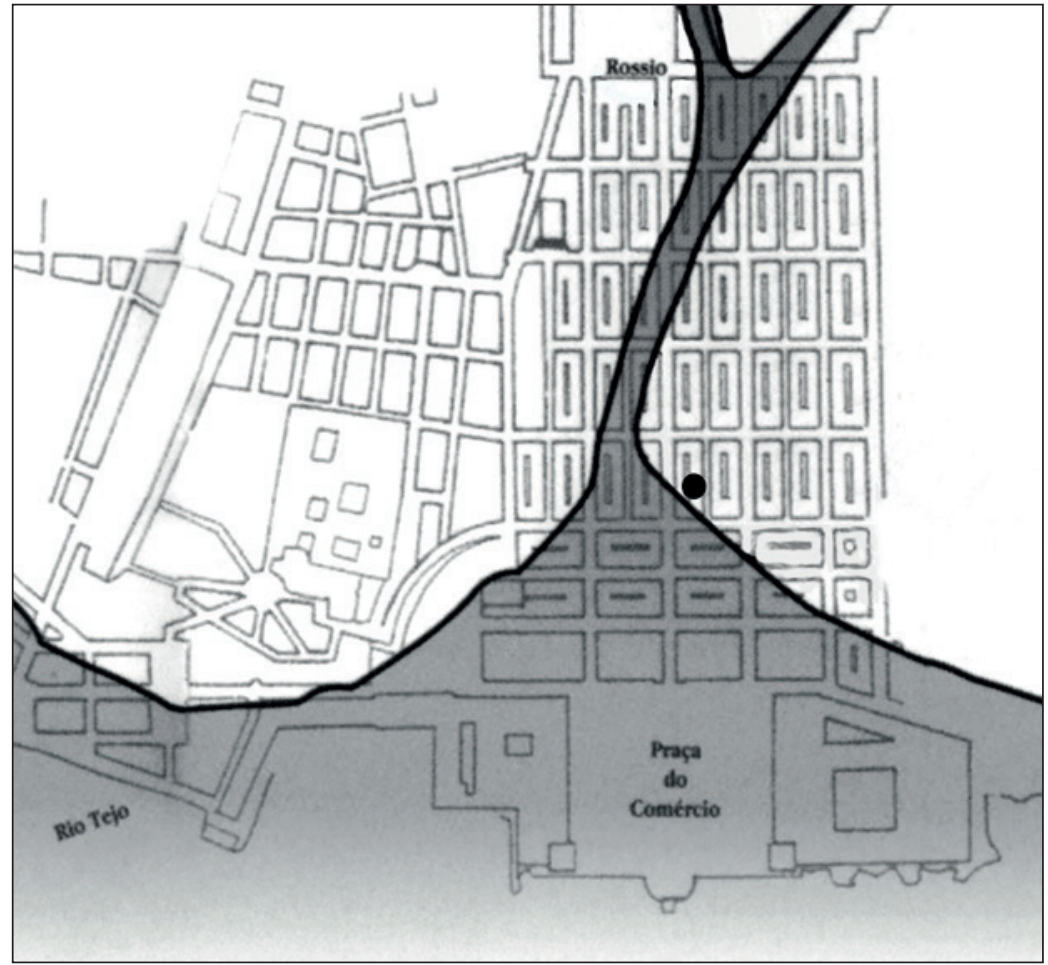




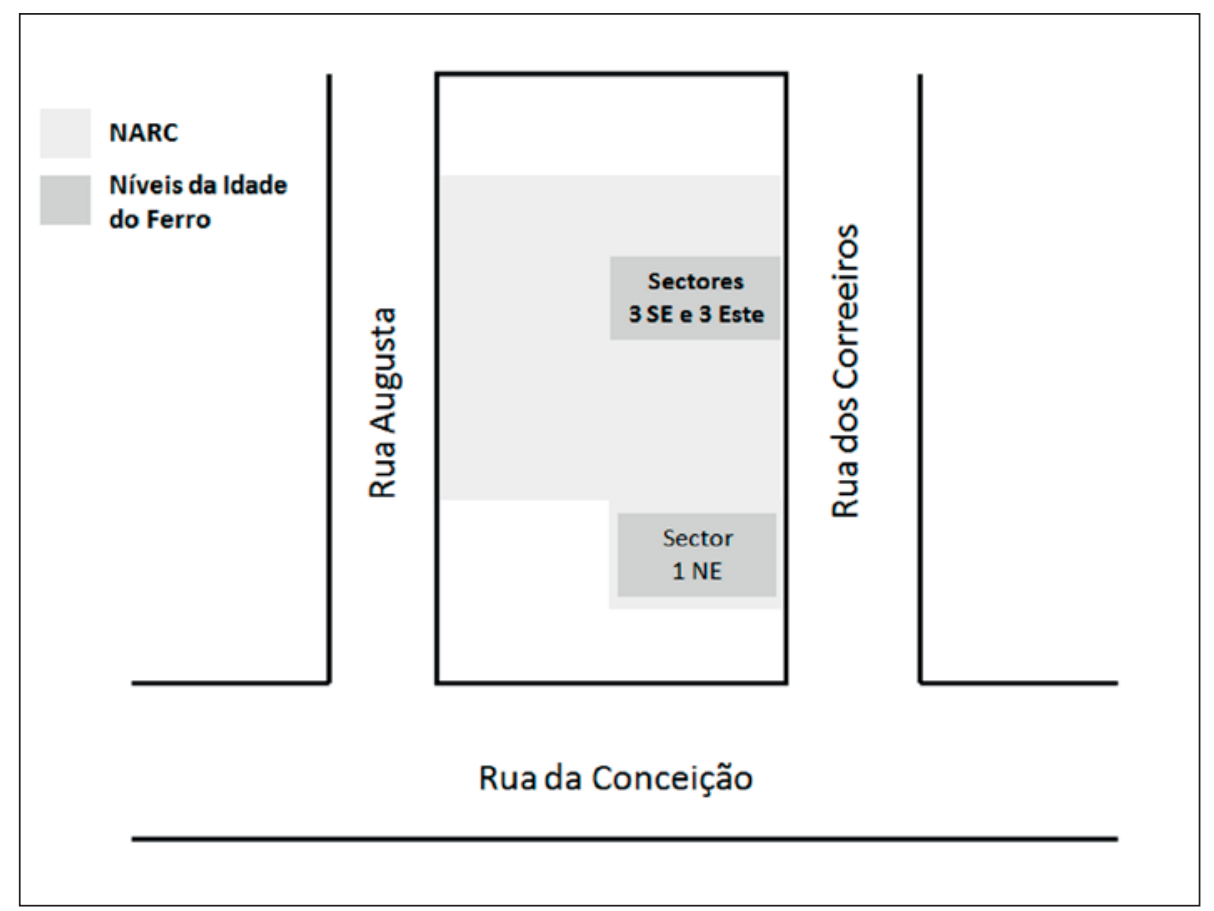

Figura 3. Localização do NARC e dos sectores com contextos da Idade do Ferro ocupacional, a intervenção compartimentada e descontínua no tempo que gerou múltiplas referências de campo e a presença permanente do nível freático que muito dificultou a leitura estratigráfica. Apesar destas dificuldades, foi proposta uma sistematização dos contextos que forneceram fauna mamalógica, a partir da interpretação estrutural/estratigráfica definida por Elisa Sousa (2014: 64-83).

A ocupação da Idade do Ferro do NARC comporta uma primeira fase de ocupação e de construção de estruturas arquitectónicas (de planta rectangular) incluindo estruturas de combustão (Fases A, B, C e D definidas por Sousa 2014), seguida de uma fase de abandono (Fase E segundo Sousa 2014), em que o local deixa de ser utilizado. Os níveis posteriores romanos estão separados por uma camada arenosa de origem natural que permite excluir a influência romana nos restos da fase de abandono.

Como foi referido, segundo Sousa (2014), é difícil adscrever uma funcionalidade específica às estruturas encontradas no NARC, tendo sido proposto que o espaço possa ter acumulado diversas funções em simultâneo, concretamente funções de cariz habitacional com outras mais directamente relacionadas com a produção oleira e, considerando as respectivas condições de implantação geográfica, até funções talvez relacionadas com actividades portuárias.

\section{METODOLOGIA DO ESTUDO DAS FAUNAS}

No caso dos moluscos foram contabilizados quando presentes a charneira, no caso dos bivalves, e apex da concha, no caso dos gastrópodes. Os restantes fragmentos de concha não foram contabilizados.

Quanto aos mamíferos contaram-se apenas os ossos ou fragmentos de ossos cuja articulação estava presente em mais de $50 \%$ ou, no caso dos dentes, quando mais $50 \%$ do elemento estava presente, tal como descrito por Detry (2007). Este método baseia-se na definição de zona diagnóstico descrita pela primeira vez por Watson (1989). Estes elementos contabilizados são representativos de todas as partes do esqueleto e são facilmente identificáveis até ao nível taxonómico específico. Evita-se também a contagem duplicada do mesmo osso, que frequentemente está fragmentado. Assim, vértebras e costelas, inteiras ou fragmentadas, foram excluídas da análise pois dificilmente se obtém uma identificação da espécie.

As identificações dos elementos osteológicos foram feitas com base na colecção de referência de um de nós (CD) complementada com a do Laboratório de Arqueociências da Direcção-Geral do Património Cultural (LARC-DGPC). 


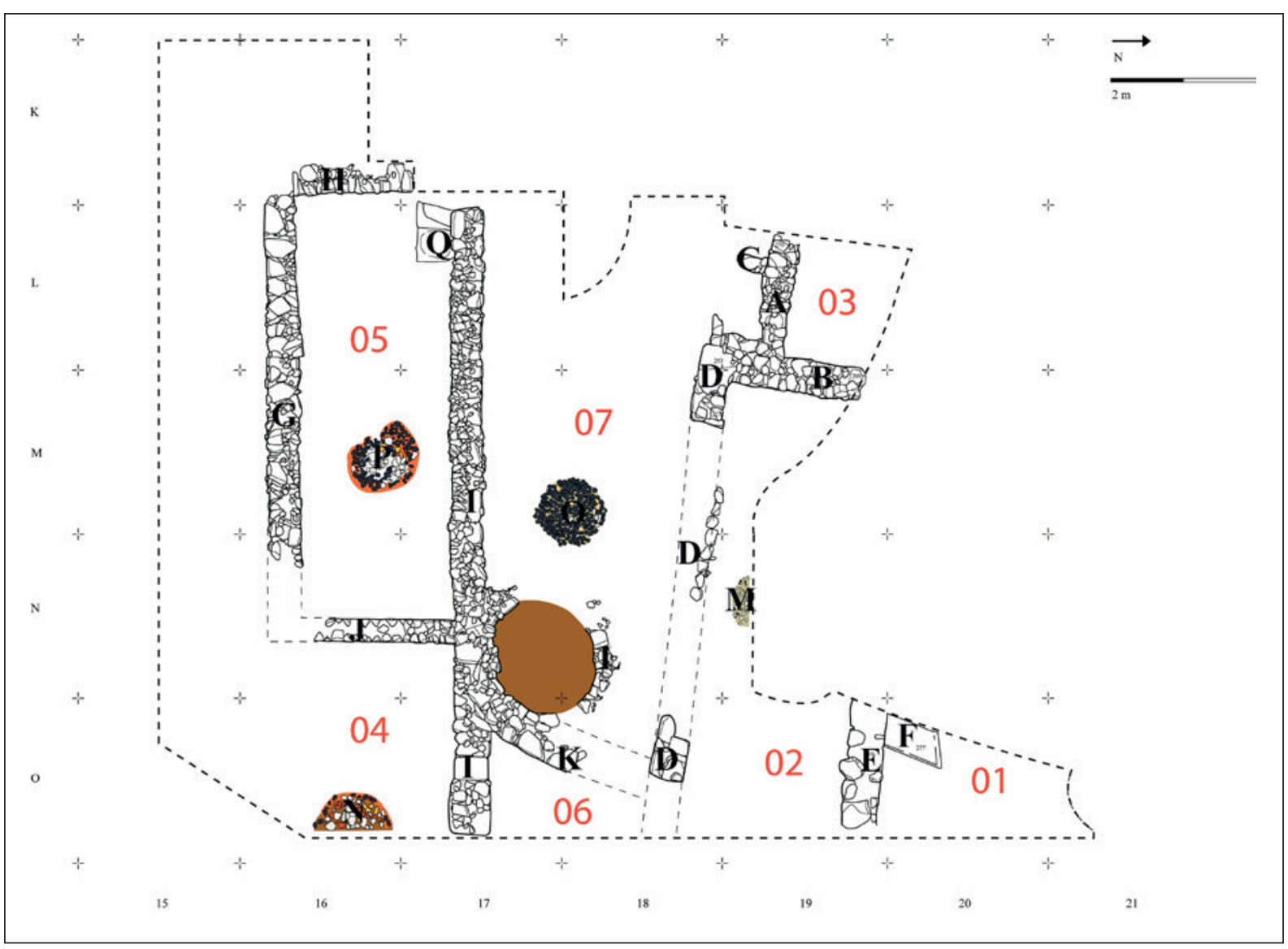

Figura 4. Compartimentos identificados no urbanismo pré-romano do NARC (adaptado de Sousa 2014: 69).

Para distinguir os ossos de ovelha (Ovis aries) de cabra (Capra hircus) foram utilizados os critérios definidos por Boessneck (1969).

As medições osteométricas utilizadas seguem os critérios definidos por Driesch (1976) e Payne e Bull (1988). Tendo sido apenas possível medir dois úmeros e uma tíbia, nomeadamente Bd (largura da articulação distal) e Dd (profundidade da articulação distal) e no caso do úmero ainda o BT (largura da tróclea distal) e HTC (altura da constrição da tróclea). Quanto aos dentes foi ainda medido o comprimento e a largura do molar $/ 1$ de cão e molar $/ 3$ de gado bovino.

O desgaste dos dentes foi registado, no caso dos caprinos, seguindo a escala de desgaste definida por Payne (1987) e posteriormente comparado com as idades de animais de uma colecção de referência, publicados por Deniz e Payne (1982).

Aspectos tafonómicos como a presença de marcas de corte e de roeduras de animais foram também registados, embora tenham sido raras as ocorrências.

\section{RESULTADOS E DISCUSSÃO}

Foram recuperados maioritariamente ossos e dentes de mamíferos (115) e ainda alguns restos de moluscos (26), não tendo sido identificados ossos de aves.

A recuperação demonstrou-se adequada e as peças apresentam-se em geral bem preservadas embora com superfícies ligeiramente erodidas.

\subsection{Moluscos}

No total foram registados 26 restos de Moluscos: 20 datam da fase de ocupação e seis da fase de abandono; 24 pertencem a Bivalves e apenas dois a Gastrópodes (ver tabela 1).

Os exemplares identificados nos níveis da Idade do Ferro, sendo na maioria atribuídos a espécies que toleram água salobra, indicam a proximidade do estuário do Tejo, o qual na época penetrava ao 


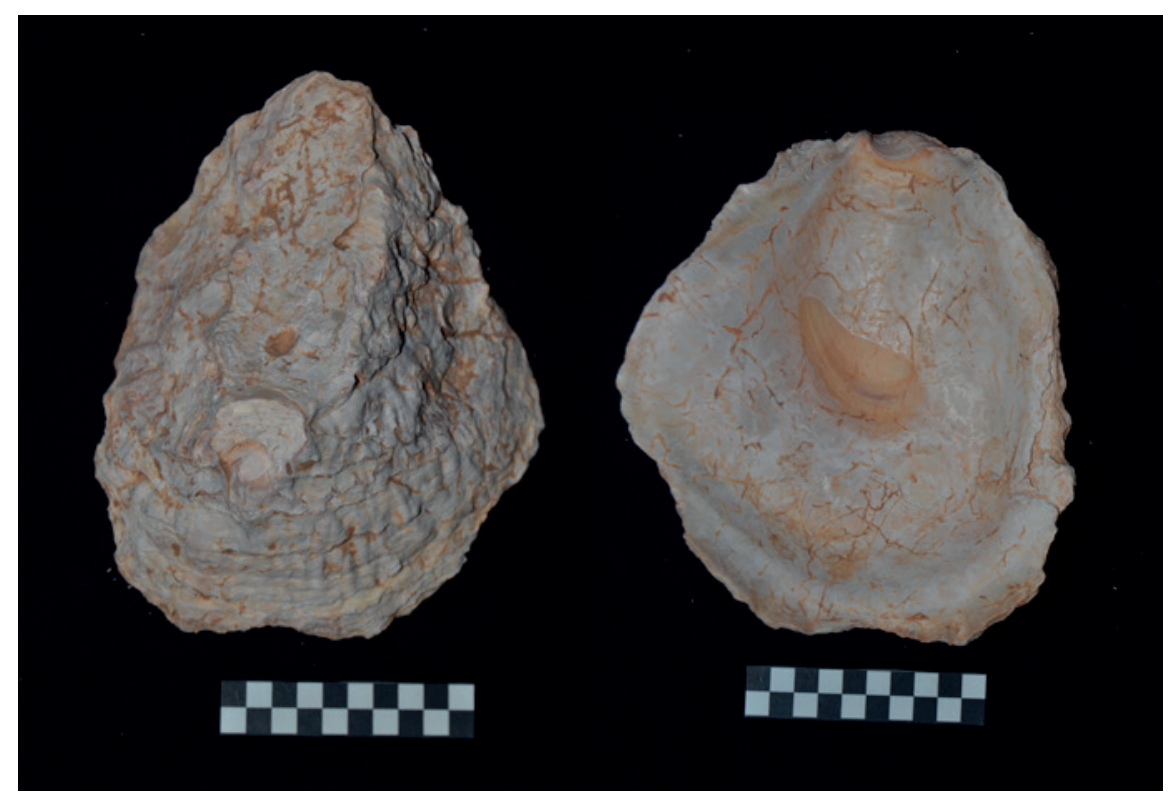

Figura 5. Face interna e externa da mesma concha de Ostrea edulis.

longo da baixa lisboeta, flanqueando o sítio arqueológico.

Tabela 1. Número de restos determinados (NRD) de Moluscos encontrados nas escavações do NARC dos níveis de idade do Ferro.

\begin{tabular}{|l|c|c|c|c|}
\cline { 2 - 5 } \multicolumn{1}{c|}{} & \multicolumn{4}{c|}{ Idade do Ferro } \\
\cline { 2 - 5 } \multicolumn{1}{c|}{} & \multicolumn{2}{c|}{$\begin{array}{c}\text { Fase de } \\
\text { ocupação }\end{array}$} & \multicolumn{2}{c|}{$\begin{array}{c}\text { Fase de } \\
\text { abandono }\end{array}$} \\
\cline { 2 - 5 } \multicolumn{1}{c|}{} & \multicolumn{2}{c|}{ NRD } & \multicolumn{2}{c|}{ NRD } \\
\cline { 2 - 5 } \multicolumn{1}{c|}{} & $\mathrm{N}$ & \multicolumn{1}{c|}{$\%$} & $\mathrm{~N}$ & $\%$ \\
\hline Patella sp & 1 & $5 \%$ & 0 & $0 \%$ \\
\hline Cerithium vulgatum & 1 & $5 \%$ & 0 & $0 \%$ \\
\hline Pecten maximus & 0 & $0 \%$ & 1 & $17 \%$ \\
\hline Ostrea edulis & 10 & $50 \%$ & 4 & $67 \%$ \\
\hline Cerastoderma edule & 1 & $5 \%$ & 0 & $0 \%$ \\
\hline Cf. Chamelea striatula & 0 & $0 \%$ & 1 & $17 \%$ \\
\hline Ruditapes decussatus & 7 & $35 \%$ & 0 & $0 \%$ \\
\hline Total & 20 & $100 \%$ & 6 & $100 \%$ \\
\hline
\end{tabular}

A espécie mais abundante é a ostra, Ostrea edulis. $\mathrm{Na}$ figura 5, podemos observar o aspecto arredondado típico da $O$. edulis, diferente da forma mais alongada da concha da Crassostrea angulata. Esta espécie seria abundante no ambiente circundante estuarino, onde poderia ser facilmente recolectada.

A amêijoa-boa (Ruditapes decussatus) é a segunda espécie mais frequente, estando ausente da fase de abandono.

À fase de ocupação pertence ainda uma valva de berbigão (Cerastoderma edule) e outra de lapa (Patella sp.). A primeira espécie relaciona-se com ambiente de interior de estuário, onde seria frequente; a segunda com ambiente marinho de elevada energia de substrato rochoso.

\subsection{Mamíferos}

Na tabela 2 pode ver-se que os mamíferos mais comuns são os grandes bovinos domésticos (Bos taurus), a ovelha (Ovis aries), a cabra (Capra hircus) e o porco/ javali (Sus sp.). Mais raramente, ocorrem ainda alguns restos de veado (Cervus elaphus), de equídeo (Equus sp.) e de cão (Canis familiaris).

Bos taurus (boi doméstico)

O bovídeo de grande porte identificado corresponde à espécie doméstica Bos taurus, já que o auroque (Bos primigenius) deixou de ser identificado desde a Idade do Bronze tanto em sítios portugueses (Cardoso 2002) como em Espanha (Castaños 1991). 
Tabela 2. Número de restos determinados (NRD) de Mamíferos encontrados nas escavações do NARC dos níveis de Idade do Ferro.

\begin{tabular}{|c|c|c|c|c|c|c|c|c|}
\hline & \multicolumn{4}{|c|}{$\begin{array}{l}\text { Idade do Ferro } \\
\text { Fase de ocupação }\end{array}$} & \multicolumn{4}{|c|}{$\begin{array}{l}\text { Idade do Ferro } \\
\text { Fase de abandono }\end{array}$} \\
\hline & \multicolumn{2}{|c|}{ NRD } & \multicolumn{2}{|c|}{ NMI } & \multicolumn{2}{|c|}{ NRD } & \multicolumn{2}{|c|}{ NMI } \\
\hline & $\mathrm{N}$ & $\%$ & $\mathrm{~N}$ & $\%$ & $\mathrm{~N}$ & $\%$ & $\mathrm{~N}$ & $\%$ \\
\hline Bos taurus & 26 & $41 \%$ & 2 & $22 \%$ & 20 & $39 \%$ & 1 & $17 \%$ \\
\hline O. aries./C. hircus & 17 & $27 \%$ & 2 & $22 \%$ & 22 & $43 \%$ & 1 & $17 \%$ \\
\hline Capra hircus & 2 & $3 \%$ & 1 & $11 \%$ & 0 & $0 \%$ & 0 & $0 \%$ \\
\hline Sus sp & 11 & $17 \%$ & 1 & $11 \%$ & 4 & $8 \%$ & 1 & $17 \%$ \\
\hline Cervus elaphus & 4 & $6 \%$ & 1 & $11 \%$ & 2 & $4 \%$ & 1 & $17 \%$ \\
\hline Equus sp & 3 & $5 \%$ & 1 & $11 \%$ & 0 & $0 \%$ & 0 & $0 \%$ \\
\hline Canis familiaris & 1 & $2 \%$ & 1 & $11 \%$ & 3 & $6 \%$ & 1 & $17 \%$ \\
\hline Total & 64 & & 9 & & 51 & & 5 & \\
\hline
\end{tabular}

Excepcionalmente, um resto recolhido nos níveis da Idade do Ferro da Sé de Lisboa foi identificado como auroque, pelo tamanho (Arruda 1999/2000: 127). Contudo, no caso em apreço, o tamanho dos ossos recuperados não se afigurou compatível com o do ancestral selvagem. Na figura 6 é possível comparar as medidas de três molares inferiores com os recolhidos na Alcáçova de Santarém (vários períodos in Davis 2006), Castro Marim (Idade do Ferro in Davis 2007) e nos concheiros de Muge (Mesolítico in Detry 2007). Nenhum dos três molares recuperados no NARC possuía medidas atribuíveis à espécie selvagem.

O gado bovino seria uma das principais fontes de carne para as populações que habitaram o local na Idade do Ferro. Mesmo durante a fase de abandono, onde os caprinos atingem um número ligeiramente superior de restos, o gado bovino representa claramente um maior contributo em termos de carne consumida.

O gado bovino podia ser ainda utilizado no transporte de bens, pessoas e alfaias agrícolas, bem como para obter leite, sendo por isso uma espécie com múltiplos proveitos e compreensível a sua preferência por estas populações.

O membro anterior e posterior estão ambos representados, mas a escassez de elementos não permite conclusões sobre a abundâncias de determinados elementos (tabela 3 e 4). Mesmo as falanges aparentemente mais frequentes no registo, devem a sua maior frequência ao facto de existirem em maior número no esqueleto (e.g. oito falanges para dois úmeros). A presença de alguns elementos dentários comprova que o crânio foi também aproveitado, correspondendo a uma parte do esqueleto com escasso interesse alimentar.

Um terceiro molar inferior inserido no osso mandibular indica, pelo desgaste avançado, a presença de um indivíduo senil. Por outro lado, os ossos apresentavam-se todos com as epífises fundidas, querendo dizer que seriam todos de animais adultos. Aspectos que reforçam a hipótese de serem utilizados secundariamente em outras actividades já acima referidas, como a tracção e a produção de leite.

\section{Ovis aries e/ou Capra hircus (ovelha e/ou cabra doméstica)}

A ovelha e/ou a cabra representam também uma parte importante dos restos, sendo o segundo táxon mais representado na fase de ocupação (30\%) mas passando para primeiro lugar (43\%) na fase de abandono.

A distinção entre as duas espécies é difícil. Apenas os chifres, úmeros, calcâneos, astrágalos e metápodos, para além de alguns elementos dentários, permitem, se bem conservados, fazer essa distinção (quando possível, seguiram-se os critérios de Boessneck 1969). Deste modo, os restos em apreço foram por isso considerados indistintamente, na larga maioria dos casos. Apenas no caso de dois úmeros foi possível identificar 


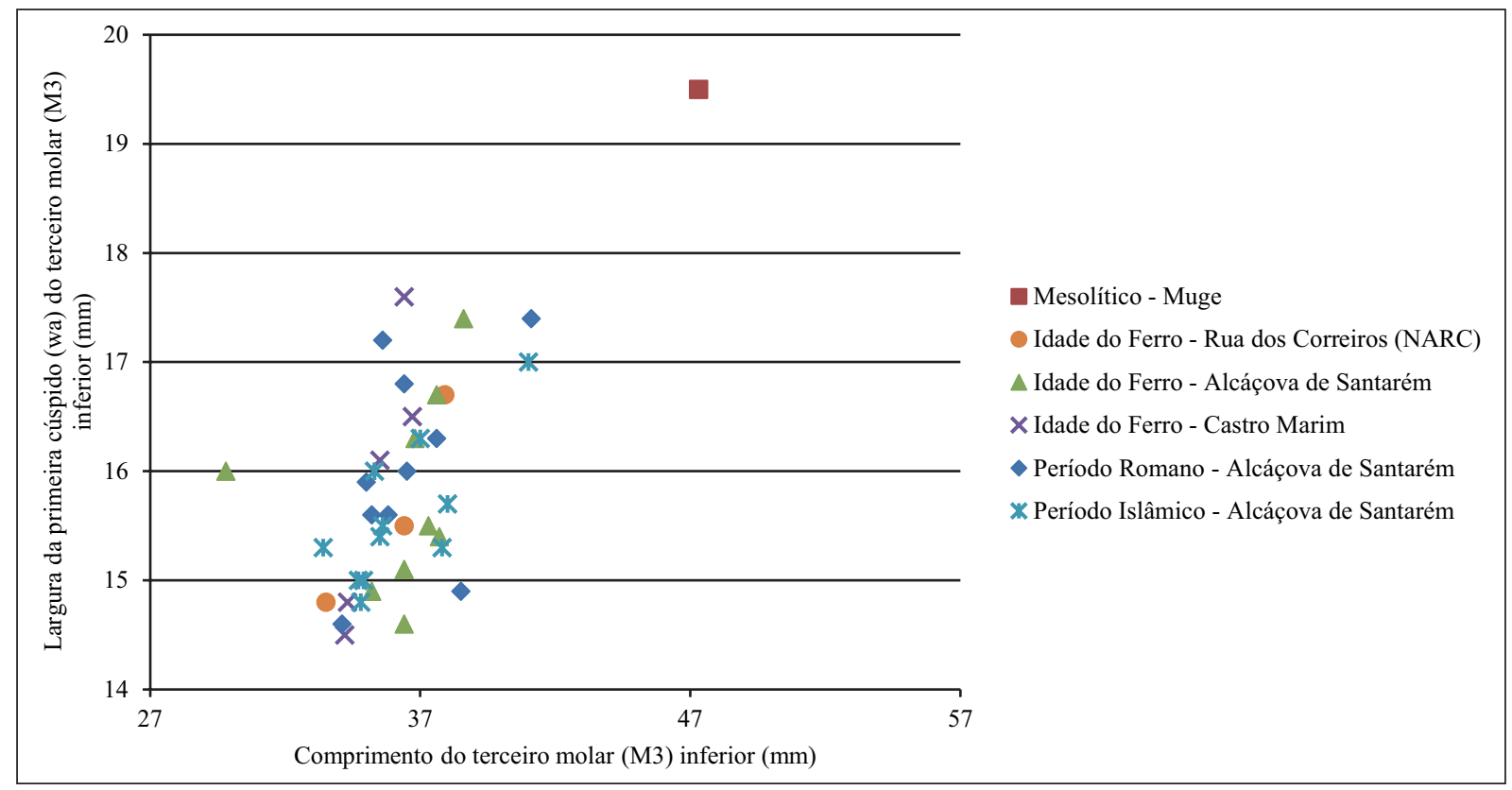

Figura 6. Largura e comprimento do terceiro molar inferior de Bos $s p$. Medidas comparativas, de Muge, Alcáçova de Santarém e Castro Marim, gentilmente cedidas por Simon Davis.

como Capra hircus, não tendo sido nenhum identificado como pertencente especificamente a ovelha. Talvez este aspecto reflicta a prevalência da cabra, mas o número reduzido da amostra não permite certeza.

A distribuição das partes do esqueleto destes pequenos bovídeos mostram que estão representadas partes da carcaça com mais carne e com menos carne, para além do crânio e muito provavelmente de costelas e vértebras (tabela 3 e 4). Deste modo, pode concluir-se que as carcaças seriam provavelmente esquartejadas nas proximidades, ou no próprio local.

Apesar da amostra ser de reduzidas dimensões, o desgaste dos dentes de uma das mandíbulas é compatível com um animal entre os 4 e 7 anos quando comparado com os resultados de Deniz e Payne (1982). A presença de outra mandíbula com um dente de leite $(\mathrm{Dp} / 4)$ mostra que este animal deveria ter menos de dois anos (ver Deniz e Payne 1982).

As epífises dos ossos longos apresentam-se quase todas fundidas, mostrando que os animais possuíam, na generalidade, idades superiores a pelo menos dois anos. A excepção é uma tíbia distal e uma porção proximal de fémur, cujas epífises não se encontravam fundidas, sendo que a primeira funde por volta dos dois anos e o segundo por volta dos três anos (Silver 1969).

Os animais poderiam ser abatidos quando atingido o seu máximo tamanho, para obter a carne, ou mantidos até mais velhos para obter produtos secundários, como o leite e, eventualmente, a lã, um conjunto tão pequeno não permite no entanto perceber se alguma das estratégias é preterida.

\section{Sus sp (porco e/ou javali)}

Os suídeos aparecem em terceiro lugar no número de restos determinados. É uma espécie presente mas menos importante para a economia alimentar destas populações.

Os restos podem pertencer tanto a javali como a porco doméstico, distinção difícil de fazer apenas com base em aspectos morfológicos, afigurando-se o tamanho como o critério mais utilizado para estabelecer a diferença, sendo o javali de maior porte que o porco. No entanto, esse critério é pouco fiável, uma vez que o javali varia muito de tamanho conforme as áreas geográficas em que vive, pelo que os exemplares peninsulares de menores dimensões podem ser confundidos com a espécie doméstica, no quadro da biometria europeia correspondente à espécie (Albarella et al. 2005).

No conjunto do NARC nenhum dos restos aparenta possuir dimensões compatíveis com a espécie selvagem. As medidas obtidas para uma tíbia $(\mathrm{Bd}-$ $28,1 \mathrm{~mm})$ e dois úmeros ( $\mathrm{Bd}-39,8 \mathrm{~mm}, 36,3 \mathrm{~mm})$ aproximam-se das correspondentes à forma doméstica, 
Tabela 3. Número de restos determinados por partes do esqueletos das espécies de mamíferos encontrado no NARC dos níveis da Idade do Ferro - Fase de ocupação.

\begin{tabular}{|c|c|c|c|c|c|c|c|}
\hline & $\begin{array}{c}\text { Bos } \\
\text { taurus }\end{array}$ & $\begin{array}{l}\text { Ovis aries ou } \\
\text { Capra hircus }\end{array}$ & $\begin{array}{l}\text { Capra } \\
\text { hircus }\end{array}$ & Sus sp & $\begin{array}{l}\text { Cervus } \\
\text { elaphus }\end{array}$ & Equus sp & $\begin{array}{c}\text { Canis } \\
\text { familiaris }\end{array}$ \\
\hline \multicolumn{8}{|l|}{ Dentes superiores } \\
\hline Pré-molar & & & & 2 & & & \\
\hline Molar & & 2 & & 2 & & & \\
\hline \multicolumn{8}{|l|}{ Dentes inferiores } \\
\hline dp4 & & 1 & & & & & \\
\hline P4 & 1 & & & & & & \\
\hline M3 & 2 & & & & & & \\
\hline $\mathrm{M} 1 / 2$ & 5 & & & & & & \\
\hline Molar & & & & & & 2 & \\
\hline Mandíbula & & & & & & & 1 \\
\hline Atlas & & & & 1 & & & \\
\hline \multicolumn{8}{|c|}{ Esqueleto apendicular } \\
\hline Omoplata distal & 1 & 2 & & 1 & & & \\
\hline Úmero distal & 1 & 2 & 2 & 1 & & & \\
\hline Rádio proximal & & 3 & & 1 & & & \\
\hline Rádio distal & & & & 1 & 2 & & \\
\hline Metacarpo proximal & 1 & 1 & & & & & \\
\hline Fémur proximal & & 2 & & & & & \\
\hline Tíbia proximal & & & & 1 & & & \\
\hline Tíbia distal & 3 & 3 & & & & & \\
\hline Astrágalo & 3 & & & 1 & & & \\
\hline Metatarso completo & 2 & & & & & & \\
\hline Metatarso proximal & 1 & 1 & & & & & \\
\hline Falange I & 5 & & & & 1 & 1 & \\
\hline Falange II & & & & & 1 & & \\
\hline Falange III & 1 & & & & & & \\
\hline TOTAL & 26 & 17 & 2 & 11 & 4 & 3 & 1 \\
\hline
\end{tabular}

esta normalmente com medidas inferiores a $30 \mathrm{~mm}$ no caso da tíbia e $40 \mathrm{~mm}$ no caso do úmero, se tivermos em conta das medidas obtidas para os suídeos do Mesolítico (Javali) e Calcolítico em Portugal por Detry (2007). É provável que os restos identificados neste contexto urbano sejam de porco, reforçando as características domésticas do conjunto.

Os segmentos anatómicos que se encontram presentes (tabela 3 e 4), sobretudo nos níveis de ocupação, encontram-se relacionados com as partes da carcaça de 
Tabela 4 . Número de restos determinados por partes do esqueletos das espécies de mamíferos encontrado no NARC dos níveis da Idade do Ferro - Fase de abandono.

\begin{tabular}{|c|c|c|c|c|c|}
\hline & Bos taurus & Ovis aries ou Capra hircus & Sus sp & Cervus elaphus & Canis familiaris \\
\hline \multicolumn{6}{|l|}{ Dentes superiores } \\
\hline Molar & 3 & 7 & & & \\
\hline \multicolumn{6}{|l|}{ Dentes inferiores } \\
\hline Canino & & & & & 1 \\
\hline P3 & 1 & & & & \\
\hline P4 & 1 & & & & \\
\hline M1 & & 2 & & & \\
\hline M2 & & 2 & & & \\
\hline M3 & 1 & 1 & & & \\
\hline $\mathrm{M} 1 / 2$ & 1 & & & & \\
\hline \multicolumn{6}{|l|}{ Esqueleto apendicular } \\
\hline Omoplata distal & 1 & & & & \\
\hline Úmero distal & & 1 & 1 & & 1 \\
\hline Rádio completo & & 1 & & & \\
\hline Rádio proximal & 1 & 2 & & & \\
\hline Ulna & & & & & 1 \\
\hline Metacárpico proximal & 1 & 1 & & 1 & \\
\hline Metacárpico distal & 1 & 1 & & & \\
\hline Fémur proximal & & 1 & & & \\
\hline Tíbia distal & & & 2 & & \\
\hline Metatársico proximal & & & 1 & 1 & \\
\hline Metatársico distal & & 1 & & & \\
\hline Falange I & 5 & 1 & & & \\
\hline Falange II & 3 & 1 & & & \\
\hline Falange III & 1 & & & & \\
\hline TOTAL & 20 & 22 & 4 & 2 & 3 \\
\hline
\end{tabular}

maior interesse alimentar, indicando que correspondem a restos de refeições e não, por exemplo, a restos de talho. Aliás, a ausência de falanges, ao contrário das outras espécies, pode querer dizer que as patas destes animais, de muito menor interesse alimentar, seriam cortadas noutro local estando aqui presentes apenas os restos resultantes da actividade alimentar da população sediada no local. Contudo, o facto da amostra ser bastante diminuta impede observações conclusivas a esse respeito.

\section{Cervus elaphus (veado)}

Os restos de veado correspondem apenas a cerca de $5 \%$ da amostra. Na fase de ocupação foram encontrados 
quatro restos, duas falanges e duas porções distais de rádio (tabela 3), que correspondem a partes do esqueleto com escassez de carne. Possivelmente, parte do esqueleto foi esquartejado neste local, havendo um desmanche primário e secundário e uso das porções com maior interesse alimentar noutro local. Do mesmo modo, dos níveis da fase de abandono provém um metatársico e um metacárpico (tabela 4), que, igualmente, correspondem a partes do esqueleto com pouca ou nenhuma carne.

\section{Equus sp (burro e/ou cavalo)}

Foram encontrados dois dentes de equídeo. A forma das dobras dos dentes pode dar indicações sobre a identificação ao nível específico. Segundo Davis (1980) podemos usar dois critérios para distinguir ao nível específico os dentes inferiores de equídeos: o nível de penetração da dobra externa para interior do dente (ver seta da fig. 7A), maior no caso do E. caballus e do $E$. hydruntinus; e a forma da dobra interna (ver seta da fig. 7A), em forma de U nos cavalos e em V no burro. Assim, na fig. 7A pode ver-se um molar ou pré-molar $(\mathrm{P} / 3$ a $\mathrm{M} / 2$ ) inferior em que a dobra externa não toca na dobra interna o que pode apontar para cavalo ou burro. Por outro lado, a dobra interna possui uma forma em $\mathrm{V}$ como é característico da espécie Equus asinus. O $\mathrm{M} / 3$ inferior da fig. 7B tem características semelhantes sendo que a dobra externa penetra ainda menos em direcção à dobra interna. É possível que estejamos perante dentes de E. asinus.

A presença de burro é confirmada em sítios orientalizantes da Idade do Ferro, como a Rocha Branca (Cardoso 1993) e Castro Marim (Davis 2007), pelo que seria natural a presença deste equídeo no local em apreço. Para além disso, a presença de $E$. asinus em Leceia, povoado calcolítico da região de Lisboa (Cardoso et al. 2013) demonstra que esta espécie tinha sido introduzida na região no decurso da segunda metade do 3. ${ }^{\circ}$ milénio a.C.

Por fim, recuperou-se uma falange I de equídeo que, pelas suas medidas (GL-74,9mm, BFd-41,8mm, $\mathrm{SD}-33,4 \mathrm{~mm}$ ), parece corresponder a cavalo Equus caballus se comparadas com as medidas publicadas em Davis et al. (2008: fig.7).

É natural encontrar os dois equídeos neste conjunto; ambos serviriam sobretudo para transportar bens e pessoas. Não foram encontradas marcas de corte e o elevado desgaste dos dentes parece confirmar que se trata de animais senis, que foram mantidos para cumprir tarefas e não para servirem na alimentação.

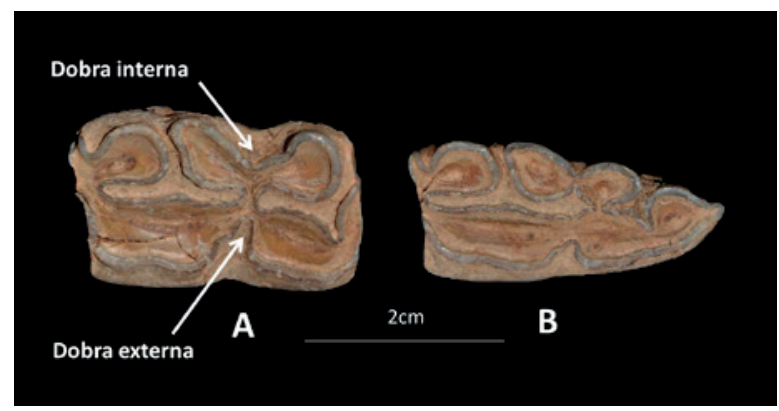

Figura 7. Dentes inferiores de equídeos.

\section{Canis familiaris (cão)}

Dentro deste pequeno conjunto foram encontrados alguns restos de cão. Presente na Ibéria em abundantes contextos domésticos desde o Mesolítico (Detry e Cardoso 2010), o seu escasso número de efectivos tem a ver com o papel diferente que desempenhava face aos restantes animais domésticos. $\mathrm{O}$ cão tem um caracter comensal que provavelmente aproveita sobretudo os restos de alimentação, sendo o seu consumo pelas comunidades humanas muito discutível, pois as marcas de corte que por vezes exibem os seus restos, como é o caso dos da Rocha Branca, em Silves (Cardoso 1993) e de Leceia (Pires et al. 2001/2002), podem relacionar-se com sacrifícios e não com o consumo primário (admitindo-se porém o consumo secundário).

Dos contextos de ocupação provém um fragmento de mandíbula com o primeiro e o segundo molares (fig. 8). Na fase de abandono, o número de restos desta espécie aumenta para três: trata-se de um fragmento de mandíbula, de uma porção distal de úmero e de uma ulna completa.

A presença de ossos roídos foi atestada apenas num caso, confirmando de forma indirecta a presença deste carnívoro (fig. 9).

Embora o carácter doméstico do conjunto indicie que se trata de cão, esta atribuição foi confirmada através das medidas obtidas no molar inferior, claramente compatíveis com a forma doméstica (fig. 10). No caso da porção distal de úmero, embora a articulação esteja destruída, as medidas obtidas também se aproximam mais do canídeo doméstico.

\subsection{Tafonomia}

A tafonomia reporta-se aos processos de integração dos restos de seres vivos na litosfera, a partir do 


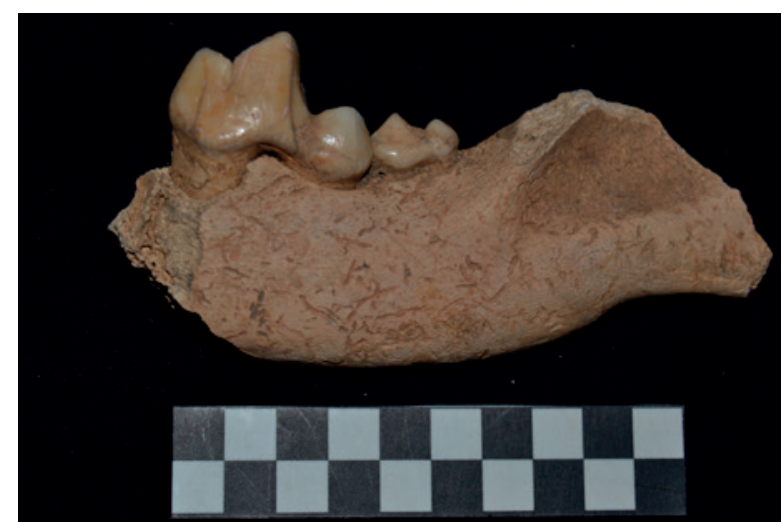

Figura 8. Fragmento de mandíbula de cão com molar 1 e 2.

momento da morte. Neste caso, serão abordados aqueles que se reportam às influências naturais, animais e antrópicas, a que os restos em apreço possam ter sido sujeitos, no decurso dos referidos processos.

Os ossos encontravam-se relativamente bem preservados mas bastante fragmentados. O facto de corresponderem a restos de alimentação explica em grande parte a sua fragmentação. O seu depósito em ambiente flúvio-estuarino ajuda também a explicar, a fragmentação e a erosão, embora ténue, que exibem.

A maior parte das fracturas observadas nos ossos longos parecem ter sido feitas ainda com o osso fresco e poucas devido à secura do osso ao ar livre. Provavelmente, após o consumo, estes restos permaneceram pouco tempo a céu aberto antes de serem enterrados, o que explica a ténue erosão ou lascamento das suas superfícies.

Quanto a modificações feitas por animais, há um caso evidente da actividade de cães, como agentes responsáveis pelas marcas observadas num úmero de caprino (fig. 9). É natural que, sendo estes animais comensais dos humanos e estando determinada a sua presença na colecção, eles tenham deixado este tipo de evidências indirectas da sua acção sobre restos já previamente consumidos pelo homem.

Apenas se encontraram marcas de corte em dois úmeros de cabra. As marcas de corte são finas e localizadas na articulação distal dos úmeros, aspecto muito comum também noutros conjuntos, já que esta articulação está associada a uma série de ligamentos. O úmero é um osso com muita carne adstrita e por isso aquela porção da carcaça é muito valorizada na dieta.

Note-se a ausência de marcas de corte mais grosseiras provocadas por cutelos, comuns em períodos posteriores como o período romano e medieval da Rua dos Correeiros (Valenzuela 2014, Moreno-García e Gabriel 2001).

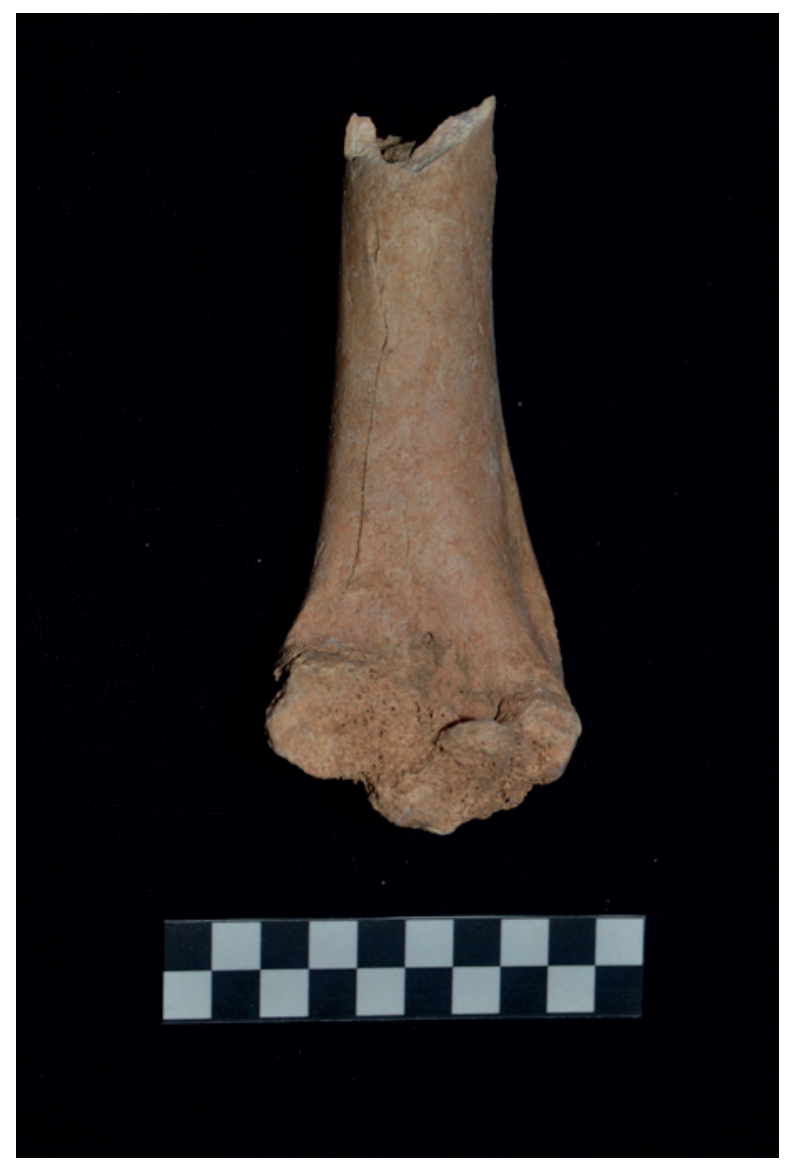

Figura 9. Extremidade distal de úmero de Ovis/Capra roído por um canídeo.

\subsection{Integração dos resultados dos restantes períodos do NARC}

Ao contrário dos intervalos cronológicos que se seguiram na baixa lisboeta, na Idade do Ferro o boi doméstico era a espécie mais abundante em termos de número de restos, embora o número mínimo de indivíduos seja equivalente ao dos caprinos.

No período romano (Valenzuela 2014) e medieval islâmico (Moreno-García e Gabriel 2001) a ovelha/cabra são os animais mais comuns, o que mostra que, por alguma razão, o gado bovino passou a ser menos utilizado na alimentação (ver fig. 11). Esta diferença é tanto mais acentuada quando se considerar que, além de serem mais frequentes os restos pertencentes a boi doméstico, também é muito assinalável a diferença de peso médio de um indivíduo desta espécie, comparativamente ao peso médio de uma ovelha ou cabra, cerca de oito vezes superior, mesmo considerando 


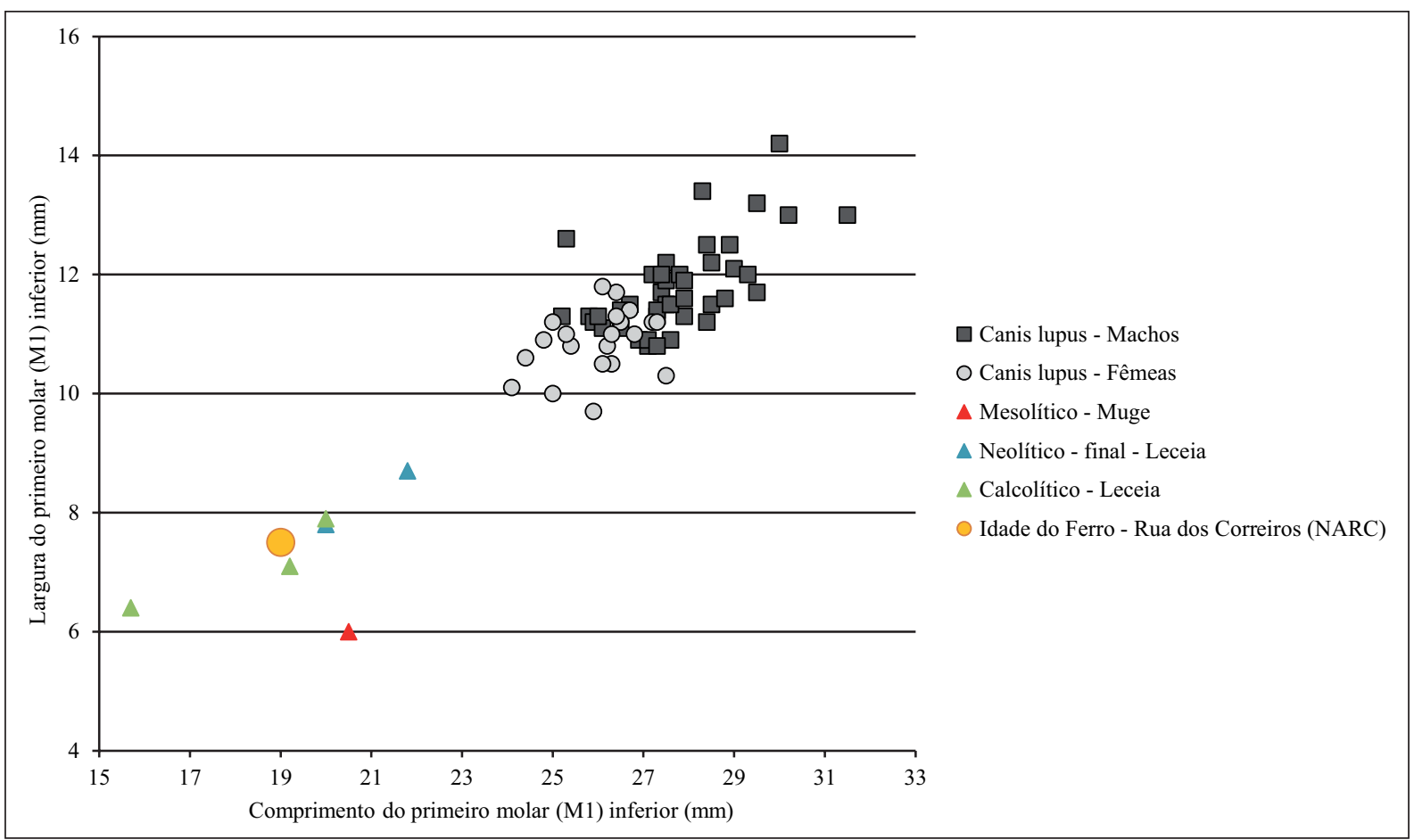

Figura 10. Largura versus comprimento do Molar 1 inferior de de cão (Mesolítico, Neolítico, Calcolítico e Idade do Ferro) e lobo (Canis lupus, colecção de referência do LARC-DGPC).

exemplares de raças não significativamente melhoradas, como a mertolenga.

A ausência de coelho nos níveis da Idade do Ferro, presente nos períodos seguintes, pode ser explicável pelo reduzido tamanho da amostra, já que nomeadamente o conjunto datado do período Romano é bastante maior, apresentando naturalmente uma maior diversidade faunística.

No período romano, os restos analisados mais frequentes correspondem aos segmentos com maior interesse alimentar. Durante o período islâmico o conjunto encontrado parece ter sido mais o resultado do esquartejamento da carcaça, com a abundância de peças com menor valor alimentar. Já durante a Idade do Ferro estão presentes todas as partes do esqueleto, demonstrando não ter existido uma especialização no aproveitamento cárnico.

A ausência de aves também pode ser indicadora de diferenças na estratégia alimentar (embora a recolha destes restos possa ter sido condicionada pela não crivagem dos sedimentos). De facto, a galinha doméstica terá sido introduzida pelos fenícios (Davis 2007) mas é sobretudo difundida e utilizada pelos romanos, sendo a partir desse período que se observa o seu aumento no registo arqueológico (e.g. Davis 2006, Detry e Arruda 2013).
A ausência de caça de pequeno porte como o coelho, lebre e ainda de galiformes selvagens como a perdiz-vermelha, ao contrário do observado período Romano (Valenzuela 2014), demonstram, a par da raridade do veado, que a actividade cinegética seria pouco relevante para a dieta destas populações.

A dependência do gado bovino e, em muito menor grau, do caprino, a que se somava a esporádica actividade cinegética, encontra paralelos em outros sítios arqueológicos da Idade do Ferro como o Cabeço Redondo (Moura) (Cardoso e Soares 2013), onde se identificou um pequeno conjunto faunístico de características semelhantes às encontradas no NARC.

\subsection{A economia alimentar na idade do Ferro em Portugal}

Durante o Calcolítico na Península Ibérica parece desenvolver-se uma agro-pecuária sobretudo dependente das espécies de menor porte como a ovelha, cabra e porco. Leceia (Cardoso e Detry 2001/2002) e Zambujal (Driesch e Boessneck 1976) são bons exemplos disso. Segundo Davis e Mataloto (2012) os sítios dos Castilejos, Castillo Alange e Papa Uvas Aljaraque, 


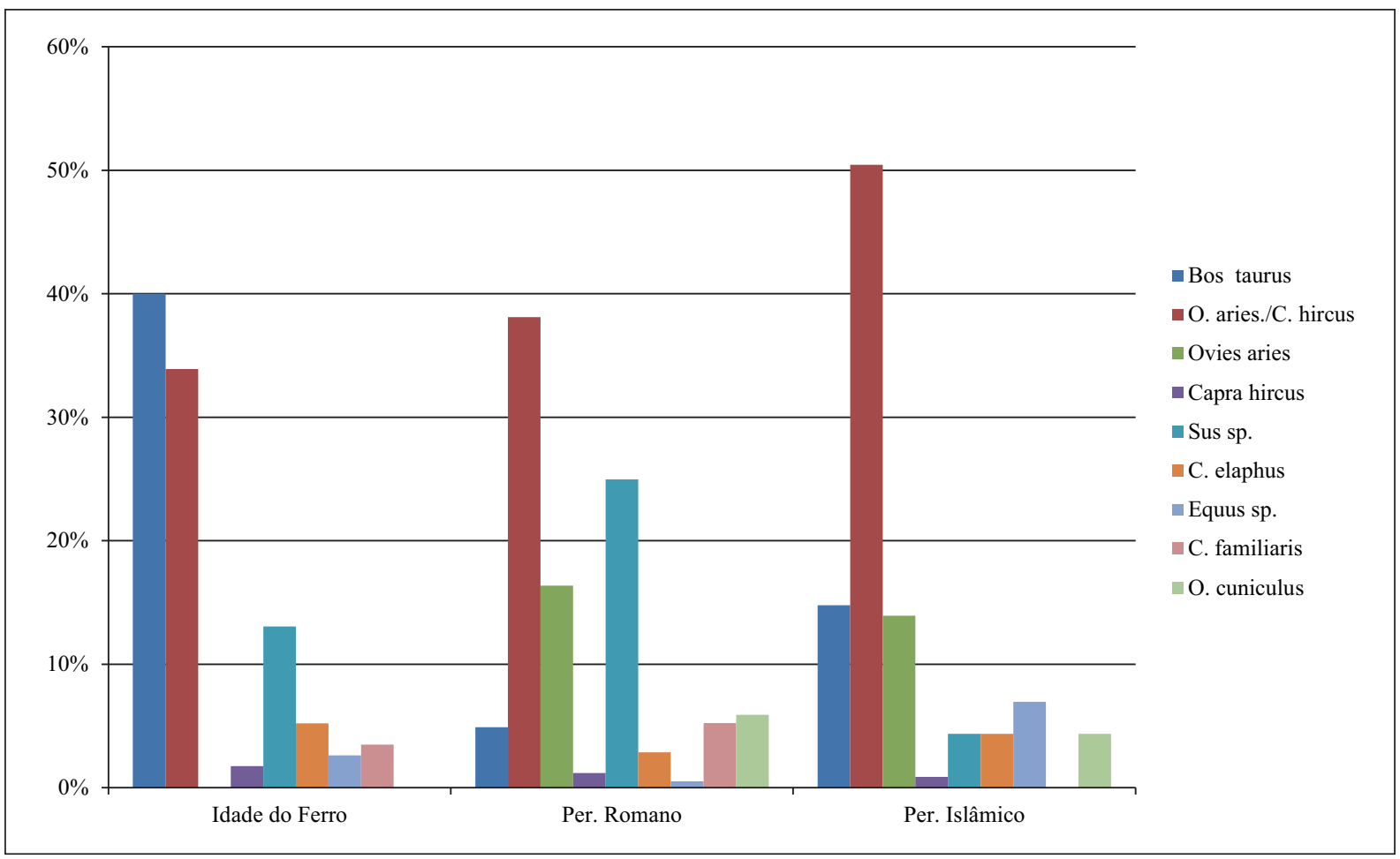

Figura 11. Percentagem de número de restos determinados (NRD) nos vários períodos de ocupação do NARC. Valores da Idade do Ferro provenientes deste mesmo artigo, do período Romano de Valenzuela (2014) e do período medieval Islâmico de Moreno-García e Gabriel (2001).

serão dos poucos sítios na Ibéria, com estudos feitos, em que o boi doméstico é a espécie preferida no Calcolítico.

Na Idade do Bronze e na Idade do Ferro o panorama parece mudar e haver uma forte prevalência dos grandes bovídeos no actual território português. Vejam-se os casos da Rocha Branca (Cardoso 1993), Almaraz (Barros et al. 1993), Alcácer do Sal (Cardoso 2000) e a feitoria fenícia de Abul (Cardoso 2001).

Segundo Cardoso $(1996,2000)$ o predomínio destes animais de grande porte pode relacionar-se com a presença de populações estáveis. No NARC, o gado bovino tem importância preponderante, à semelhança dos sítios acima referidos, corroborando a estabilidade da população ali sediada, claramente evidenciada pelos indicadores arqueológicos conhecidos.

Parece, no entanto, haver nalguns casos tendência para uma maior utilização de caprinos no sul. De facto, em Lagos (Monte Molião), os caprinos são bem mais frequentes nos estratos datados da Idade do Ferro, bem como nos seguintes do período Romano (Detry e Arruda 2013). No sítio da Mesa dos Castelinhos (Almodôvar) os caprinos são mais frequentes na Idade do Ferro, mas quase equilibrados com o número de restos de boi doméstico. No caso dos animais de maior porte estes seriam sobretudo utilizados como força de trabalho e decrescem de importância nos períodos seguintes. Por outro lado, neste mesmo sítio, a caça tem uma grande prevalência na Idade do Ferro que se acentua no período Romano (Valenzuela e Fabião 2013).

Provavelmente o conjunto observado no NARC será combinação da consequência do sedentarismo da população e investimento em animais de maior porte, bem como melhor adaptabilidade ambiental desta espécie doméstica à região de Lisboa. $\mathrm{O}$ menor número de animais caçados pode ser resultado da destruição de habitat, nomeadamente da destruição de florestas provavelmente para agricultura, a que acresce a reduzida disponibilidade/capacidade destas populações, essencialmente de natureza mercantil em desenvolverem actividades cinegéticas.

\section{CONCLUSÃO}

Sendo a amostra aqui analisada de reduzido tamanho, é ainda assim uma valiosa contribuição para o conhecimento sobre o uso e gestão de animais na Idade do 
Ferro de um contexto urbano de pendor mercantil e marítimo do século $\mathrm{V}$ a.C.

Os restos estudados parecem ser produto - exceptuando o cão - da actividade alimentar, embora no caso do gado bovino e equino, os animais pudessem ser usados concomitantemente para transporte de bens, pessoas e como força de tracção de alfaias agrícolas.

Estas populações consumiam quase exclusivamente animais domésticos (gado bovino, caprino e suíno); só esporadicamente recorriam ao consumo de animais selvagens, designadamente do veado.

Por outro lado, a sua economia não se afigura especialmente complexa nem especializada. Quanto aos restos de fauna, o NARC parece ser muito similar a outros pequenos povoados da Idade do Ferro do sul de Portugal, com base na escassa informação disponível.

\section{Agradecimentos}

Agradecemos a Elisa Sousa, pela revisão de fases iniciais do manuscrito; a Sílvia Valenzuela-Lamas, por informações sobre o conjunto faunístico do período romano; e a Simon Davis, por ter cedido medidas comparativas. Por fim, ao Laboratório de Arqueociências da DGPC, pelo acesso às colecções de referência que foram essenciais à conclusão deste trabalho.

Agradecemos à Fundação Millennium bcp, mecenas das escavações e gestora do Núcleo Arqueológico da Rua dos Correeiros, e ao Museu Nacional de Arqueologia, onde a colecção está depositada.

\section{REFERENCIAS}

Arruda, A. M. (1999/2000): Los Fenicios en Portugal. Cuadernos de Arqueología Mediterránea 5/6 Barcelona, Publicaciones del Laboratorio de Arqueología/Universidad Pompeu Fabra.

Barros, L.; Cardoso, J.L. e Sabrosa, A. (1993): "Fenícios na margem sul do Tejo. Economia e integração cultural do povoado do Almaraz - Almada", in Actas do Encontro de Estudos "Os Fenícios no Território Português”. Estudos Orientais 4: 143-181. Lisboa (1992). Lisboa, Instituto Oriental.

Boessneck, J. (1969): “Osteological differences between sheep (Ovis aries Linné) and goat (Capra hircus Linné)", in Science in Archaeology. A survey of progress and research: 331-358. London, Thames\&Hudson.
Bugalhão, J. (2001): A indústria romana de transformação e conserva de peixe em Olisipo. Núcleo Arqueológico da Rua dos Correeiros. Trabalhos de Arqueologia 15. Lisboa, Instituto Português de Arqueologia.

Cardoso, J. L. (1993): “Contribuição para o conhecimento da alimentação em contexto fenício. Estudo dos restos da Rocha Branca (Silves)". Estudos Orientais 4: 109-126.

Cardoso, J. L. (1996): "Bases de subsistência em povoados do Bronze Final e da Idade do Ferro do território português. O testemunho dos mamíferos", en J. de Alarcão (coord.), De Ulisses a Viriato. $O$ primeiro milénio a. C. Catálogo da exposição realizada no Museu Nacional de Arqueologia: 160-170. Lisboa, Instituto Português de Museus.

Cardoso, J. L. (2000): "Fenícios e indígenas em Rocha Branca, Abul, Alcácer do Sal, Almaraz e Santarém. Estudo comparado dos mamíferos", in M. E. AubetSemmler, (coord.), Actas IV Congreso Internacional de Estudios Fenicios y Púnicos 1: 319-327. Cádiz (1995), Cádiz, Universidad de Cádiz.

Cardoso, J. L. (2001): "Les mammifères d'Abul”, in F. Mayet e C. Tavares da Silva (eds.), L'Établissement phénicien d'Abul (Portugal): 281-291. Paris, Diffusion E. De Boccard.

Cardoso, J. L. (2002): “Arqueofaunas: balanço da sua investigação em Portugal”. Arqueologia e História 54: 281-298.

Cardoso, J. L. e Detry, C. (2001/2002): "Estudo Arqueozoológico dos restos de ungulados do povoado pré-histórico de Leceia (Oeiras)". Estudos Arqueológicos de Oeiras 10: 131-182.

Cardoso, J.L. e Soares, R. (2013): "Faunas Mamalógicas do Sítio Pós-Orientalizante do Cabeço Redondo (Sobral da Adiça, Moura)". Almadan 18 (II Série): 87-92.

Cardoso, J. L.; Vilstrup, J. T.; Eisenmann, J. T. e Orlando, L. (2013): "First evidence of Equus asinus L. in the Chalcolithic disputes the Phoenicians as the first to introduce donkeys into the Iberian Peninsula". Journal of Archaeological Science 40(12): 4483-4490. http://www.sciencedirect.com/science/ article/pii/S0305440313002550.

Castaños, P. (1991): "Animales domésticos y salvajes en Extremadura. Origen y evolución”. Revista de Estudios Extremeños 47: 9-67.

Davis, S. (1980): "Late Pleistocene and Holocene equid remains from Israel". Zoological Journal of the Linnean Society 70: 289-312.

Davis, S. (2006): Faunal remains from Alcáçova de Santarém (Portugal). Trabalhos de Arqueologia. Lisboa, IPA (Instituto Português de Arqueologia). 
Davis, S. (2007): The mammals and birds from the Iron Age and Roman periods of Castro Marim, Algarve, Portugal. Trabalhos do CIPA (Centro de Investigação em Paleoecologia humana e Arqueociências) 107. Lisboa, IPA (Instituto Português de Arqueologia).

Davis, S.; Gonçalves, M.J. e Gabriel, S. (2008): “Animal remains from a Moslem period (12th/13th century AD) lixeira (garbage dump) in Silves, Algarve, Portugal". Revista Portuguesa de Arqueologia 11(1): 183-258.

Davis, S. J. M. e Mataloto, R. (2012): “Animal remains from Chalcolithic São Pedro (Redondo, Alentejo): evidence for a crisis in the Mesolithic". Revista Portuguesa de Arqueologia 15: 47-85.

Deniz, E. e Payne, S. (1982): "Eruption and wear in the mandibular dentition as a guide to ageing Turkish angora goats", in B. Wilson; C. Grigson e S. Payne (eds.), Ageing and sexing animal bones from archaeological sites, BAR British Series 189: 155-205.

Detry, C. (2007): Paleoecologia e Paleoeconomia do Baixo Tejo no Mesolítico Final: O contributo do estudo dos mamíferos dos concheiros de Muge. Tese de doutoramento, Universidade Autónoma de Lisboa e Universidade de Salamanca. Inédito.

Detry, C. e Cardoso, J. L. (2010): "On some remains of $\operatorname{dog}$ (Canis familiaris) from the Mesolithic shell-middens of Muge, Portugal". Journal Archaeological Science 37(11): 2762-2774. http://www.sciencedirect.com/science/article/pii/ S0305440310001974. Detry, C. e Arruda, A.M. (2013): "A fauna da Idade do Ferro e Época romana de Monte Molião (Lagos, Algarve): continuidades e rupturas na dieta alimentar". Revista Portuguesa de Arqueologia 15: 215-227.

Driesch, A. von den (1976): A guide to the measurement of animal bones from archaeological sites. Harvard University, Peabody Museum of Archaeology and Ethnology.

Driesch, A. von den e Boessneck, J. (1976): "Die fauna vom Castro do Zambujal (fundmaterial der Grabungen von 1966 bis 1973 mit ausnahme der Zwingerfunde)", in A. von den Driesch; J. Boessneck (eds.), Studien über fruhe Tierknochenfunde von der Iberischen Halbinsel 5: 4-129. Institut fur Palaeoanatomie, Domestikationsforschung und Geschichte der Tiermedizin der Universität Munchen. München, Deutsches Archaologisches Institut, Abteilung Madrid.

Moreno-García, M. e Gabriel, S. (2001): "Faunal remains from 3 islamic contexts at Núcleo Arqueológico da Rua dos Correeiros, Lisbon". Trabalhos do CIPA (Centro de Investigação em Paleoecologia humana e Arqueociências) 20. Lisboa, IPA (Instituto Português de Arqueologia).

Payne, S. (1987): "Reference codes for wear states in the mandibular teeth of sheep and goats". Journal of Archaeological Science 14: 609-614. http://www.sciencedirect.com/science/article/ pii/0305440387900793.

Pires, F.; Cardoso, J. L. e Petrucci-Fonseca, F. (2001/2002): "Estudo Arqueozoológico dos carnívoros do povoado pré-histórico de Leceia (Oeiras)". Estudos Arqueológicos de Oeiras 10: 183-247.

Sousa, E. (2014): A ocupação pré-romana da foz do estuário do Tejo. Estudos e Memórias 7. Lisboa, Centro de Arqueologia da Universidade de Lisboa.

Valenzuela, S. (2014): "Mammal remains from the Governor's House (Belém Tower, Lisbon) and Rua dos Correeiros (Baixa, Lisbon) in the context of fish processing factories in Lusitania", in C. Detry e R. Dias (eds.), Proceedings of the First Zooarchaeology Conference in Portugal. British Archaeological Reports 2662: 57-68. Oxford, Archaeopress.

Valenzuela, S. e Fabião, C. (2012): "Ciervos, ovejas y vacas: el registo faunístico de Mesas do Castelinho (Almodôvar) entre la Edad del Hierro y Época Romana", in V Encontro de Arqueologia do Sudoeste Peninsular: 413-432. Almodôvar, Câmara Municipal de Almodôvar.

Watson, J. P. N. (1979): "The estimation of the relative frequencies of mammalian species: Khirokitia 1972". Journal of Archaeological Science 6: 127138. http://www.sciencedirect.com/science/article/ pii/030544037990058X. 